\title{
Breast Cancer Metastasis Presenting as Conjunctival Chemosis
}

\author{
Eva Diltoer Marcel P.M. ten Tusscher \\ Department of Ophthalmology, University Hospital, Vrije Universiteit Brussel, \\ Brussels, Belgium
}

\section{Key Words}

Breast cancer · Orbital metastasis · Conjunctival chemosis

\begin{abstract}
A 72-year-old woman presented with a painful right eye. A few weeks before, she had noticed a red, swollen area in the conjunctiva of the same eye. On slit lamp examination, it appeared as chemosis and vascular injection; artificial tears were prescribed. A month later, a firm mass developed on the superotemporal orbital rim, in the area of the lacrimal gland. A CT scan revealed infiltrative structures in both the left and right orbit, with contrast staining in the right lacrimal gland and near the left optic nerve. A biopsy was taken of the conjunctival swelling as well as of the lacrimal gland. Both tissues showed infiltration with lobular breast carcinoma metastases.

\section{Introduction}

According to the World Health Organization, breast cancer is the most commonly diagnosed cancer worldwide. In Western countries, women have a lifetime risk of approximately $10 \%$ to develop breast carcinoma [1].

The prevalence of metastases of breast carcinoma to the eye orbit is $4.6 \%$ [2]. In order of declining frequency, ocular metastases of breast carcinoma appear in the highly vascular choroid, the anterior segment, orbital structures and the optic nerve [1]. For orbital metastasis, orbital fat and extraocular muscles are the predilection areas [3]. Of all orbital metastases, breast carcinoma is considered to be the most prevalent primary tumor, accounting for $29-70 \%$ [4]. The presence of metastases in this area usually reflects widespread hematogenous distribution, resulting in a poor prognosis [4]. In $20-40 \%$ of the patients, ocular metastases are bilateral [1].

KARGER 125/s $\quad \begin{aligned} & \text { Prof. Dr. Marcel P.M. ten Tusscher } \\ & \text { Department of Ophthalmology } \\ & \text { Vrije Universiteit Brussel } \\ & \text { Laarbeeklaan 101, BE-1090 Brussels (Belgium) } \\ & \text { E-Mail marcel.tentusscher @ uzbrussel.be }\end{aligned}$


Diltoer and ten Tusscher: Breast Cancer Metastasis Presenting as Conjunctival Chemosis

\section{Case Presentation}

Twenty-five years after a primary diagnosis of breast carcinoma, a 72-year-old woman was sent to the ophthalmology department because of a painful right eye. A few weeks before, she had noticed a swelling on the temporal conjunctiva of that same eye. She had a history of lobular breast cell carcinoma of the right breast and had undergone lumpectomy with lymphadenectomy and adjuvant radiotherapy.

Visual acuity of the right eye was known to be low due to esotropia and amblyopia. The visual acuity of the left eye was $20 / 20$. There was no relative afferent pupillary defect. Slit lamp examination of the right eye showed chemosis with dilated vessels in the inferior temporal conjunctiva (fig. 1). The swelling was thought to hinder a normal tear film formation, giving rise to insufficient lubrication and causing the pain sensation. Artificial tears were prescribed. One month later, she visited the outpatient clinic because of a firm swelling, located at the superotemporal border of the right orbit, near the lacrimal gland. A CT scan showed unclear diffuse infiltration of the right and left orbit with staining of contrast in the lacrimal gland on the right side, as well as the retrobulbar area near the left optic nerve. A biopsy of the temporal conjunctival swelling and of the lacrimal gland of the right eye revealed lobular breast carcinoma metastases (fig. 2), confirmed with the immunohistochemical markers cytokeratine-7 and estrogen receptor.

\section{Discussion}

The present case describes a 72-year-old woman with metastatic breast carcinoma to the bulbar conjunctiva and the lacrimal gland of the right eye. Secondary tumors to the conjunctiva are extremely seldom and rarely mentioned in reviews on ocular metastases. A literature search revealed three papers with a total of six patients who showed a conjunctival metastatic lesion from breast carcinoma [5-7]. Patients presented with nonsuspect symptoms like a red eye, foreign body sensation, conjunctival swelling or a painless lesion with irregular and indistinct margins which was associated with dilated conjunctival vessels. Metastatic lesions to the lacrimal gland are also quite rare. In patients with a lacrimal gland lesion, metastasis counted for $0.9 \%$, all of which were due to secondary breast carcinoma [8].

In conclusion, patients with a history of breast carcinoma may present with nonsuspect complaints, like conjunctival swelling, a lump, a red eye or foreign body sensation, which nevertheless may turn out to be breast cancer metastases, even 25 years after the initial diagnosis. Unfortunately, prognosis of breast cancer metastasis to the conjunctiva is poor, and most of the described patients died weeks to months after the diagnosis.

\section{Disclosure Statement}

The authors have no conflict of interest to declare, nor sponsorships or funding to disclose.

\section{Statement of Ethics}

The patient described has given her informed consent. 
Case Reports in

Ophthalmology

\begin{tabular}{l|l}
\hline Case Rep Ophthalmol 2015;6:439-442 \\
\hline DOI: $10.1159 / 000442519$ & $\begin{array}{l}\text { (c) } 2015 \text { The Author(s). Published by S. Karger AG, Basel } \\
\text { www.karger.com/cop }\end{array}$ \\
\hline
\end{tabular}

Diltoer and ten Tusscher: Breast Cancer Metastasis Presenting as Conjunctival Chemosis

\section{References}

$\checkmark 1$ Dieing A, Schulz CO, Schmid P, Roever AC, Lehenbauer-Dehm S, Jehn C, Flath B, Possinger K: Orbital metastases in breast cancer: report of two cases and review of the literature. J Cancer Res Clin Oncol 2004;130:745-748.

-2 Kreusel KM, Wiegel T, Stange M, Bornfeld N, Foerster MH: Intraocular metastases of metastatic breast carcinoma in the woman. Incidence, risk factors and therapy. Ophthalmologe 2000;97:342-346.

-3 Ahmad SM, Esmaeli B: Metastatic tumors of the orbit and ocular adnexa. Curr Opin Ophthalmol 2007;18:405-413.

4 Shields JA, Shields CL, Brotman HK, Carvalho C, Perez N, Eagle RC Jr: Cancer metastatic to the orbit: the 2000 Robert M. Curts Lecture. Ophthal Plast Reconstr Surg 2001;17:346-354.

5 Kiratli H, Shields CL, Shields JA, DePotter P: Metastatic tumours to the conjunctiva: report of 10 cases. Br J Ophthalmol 1996;80:5-8.

6 Skalicky SE, Hirst LW, Conway RM: Metastatic breast carcinoma presenting as a conjunctival lesion. Clin Experiment Ophthalmol 2007;35:767-769.

7 Radovanović AB, Rasić D, Buta M, Dzodić R: Breast cancer metastasis to conjunctiva. Vojnosanit Pregl 2013;70:331-334.

8 Font RL, Smith SL, Bryan RG: Malignant epithelial tumors of the lacrimal gland: a clinicopathologic study of 21 cases. Arch Ophthalmol 1998;116:613-616.

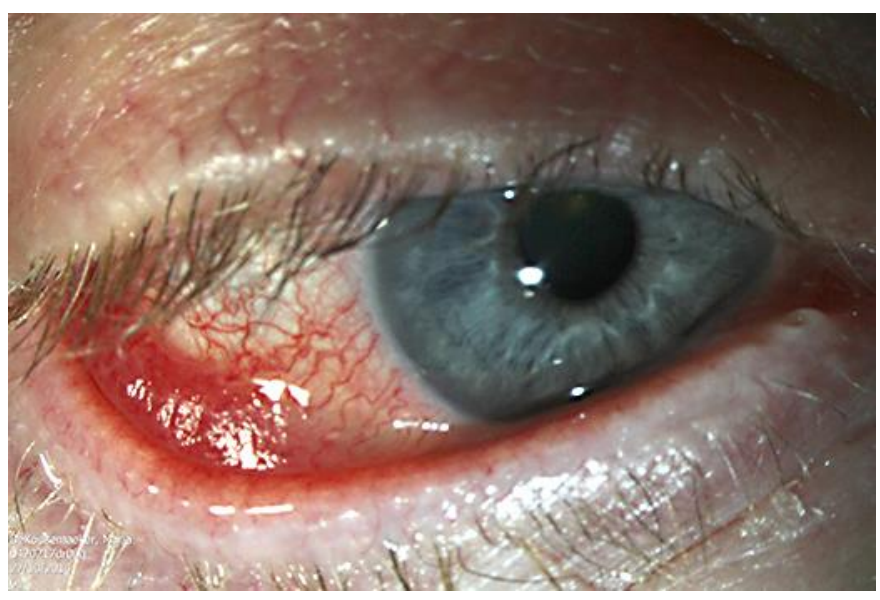

Fig. 1. The temporal bulbar conjunctiva of the right eye shows swelling and vascular dilation. 


\section{Case Reports in \\ Ophthalmology}

\begin{tabular}{l|l}
\hline Case Rep Ophthalmol 2015;6:439-442 \\
\hline DOI: 10.1159/000442519 & $\begin{array}{l}\text { C } 2015 \text { The Author(s). Published by S. Karger AG, Basel } \\
\text { www.karger.com/cop }\end{array}$ \\
\hline
\end{tabular}

Diltoer and ten Tusscher: Breast Cancer Metastasis Presenting as Conjunctival Chemosis

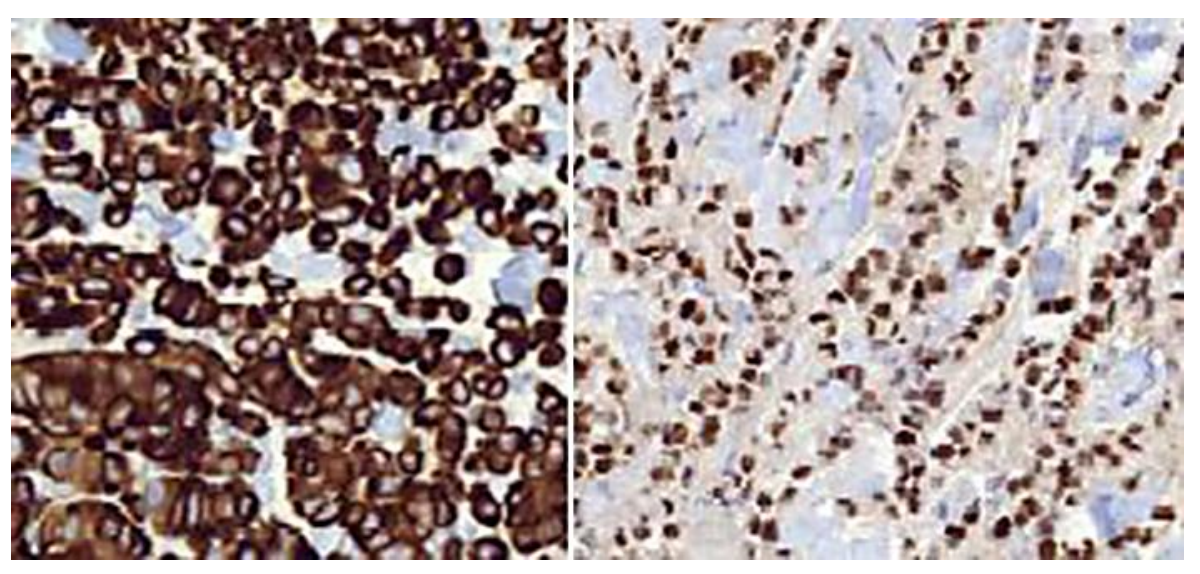

Fig. 2. Immunohistochemical expression of cytokeratin-7 in the cytoplasm of the metastatic cancer cells (left) and expression of estrogen receptor in the nuclei of the cells (right) as evidence of their primary breast origin. 